\title{
Light-absorbing soluble organic aerosol in Los Angeles and Atlanta: A contrast in secondary organic aerosol
}

\author{
Xiaolu Zhang, ${ }^{1}$ Ying-Hsuan Lin, ${ }^{2}$ Jason D. Surratt, ${ }^{2}$ Peter Zotter, ${ }^{3}$ Andre S. H. Prévôt, ${ }^{3}$ \\ and Rodney J. Weber ${ }^{1}$
}

Received 19 August 2011; revised 7 October 2011; accepted 11 October 2011; published 9 November 2011.

[1] Light absorption spectra and carbon mass of fine particle water-soluble components were measured during the summer of 2010 in the Los Angeles (LA) basin, California, and Atlanta, Georgia. Fresh LA secondary organic carbon had a consistent brown color and a bulk absorption per soluble carbon mass at $365 \mathrm{~nm}$ that was 4 to 6 times higher than freshly-formed Atlanta soluble organic carbon. Radiocarbon measurements of filter samples show that LA secondary organic aerosol (SOA) was mainly from fossil carbon and chemical analysis of aqueous filter extracts identified nitroaromatics as one component of LA brown SOA. Interpreting soluble brown carbon as a property of freshly-formed anthropogenic SOA, the difference in absorption per carbon mass between these two cities suggests most fresh secondary water-soluble organic carbon formed within Atlanta is not from an anthropogenic process similar to LA. Contrasting emissions of biogenic volatile organic compounds may account for these differences. Citation: Zhang, X., Y.-H. Lin, J. D. Surratt, P. Zotter, A. S. H. Prévôt, and R. J. Weber (2011), Light-absorbing soluble organic aerosol in Los Angeles and Atlanta: A contrast in secondary organic aerosol, Geophys. Res. Lett., 38, L21810, doi:10.1029/2011GL049385.

\section{Introduction}

[2] Organic carbon that preferentially absorbs light from UV to lower visible wavelengths appears brown and is one light-absorbing component of atmospheric aerosols [Andreae and Gelencser, 2006]. Brown carbon is emitted from primary sources (e.g., incomplete combustion [Hecobian et al., 2010]), and generated as secondary aerosol components through reactions that often involve nitrogen [Shapiro et al., 2009; Bones et al., 2010]. Brown carbon may influence photochemical processes [Jacobson, 1999] and regional radiative forcing [Park et al., 2010], and can be toxic due to the soluble nitro-aromatics formed from PAHs [Gupta et al., 1996].

[3] Particle light absorption coefficients $\left(b_{a p}\right)$ are typically measured using optical instruments at a fixed number of wavelengths, making quantifying brown carbon difficult given that black carbon (BC) and brown carbon are measured

\footnotetext{
${ }^{1}$ School of Earth and Atmospheric Sciences, Georgia Institute of Technology, Atlanta, Georgia, USA.

${ }^{2}$ Department of Environmental Sciences and Engineering, Gillings School of Global Public Heath, University of North Carolina, Chapel Hill, North Carolina, USA.

${ }^{3}$ Laboratory of Atmospheric Chemistry, Paul Scherrer Institut, Villigen, Switzerland.

Copyright 2011 by the American Geophysical Union. 0094-8276/11/2011GL049385
}

together [Sandradewi et al., 2008], along with possible confounding factors such as lensing by shells formed over BC cores and limited information on the complete absorption spectra over wide wavelength range. Measurement of soluble brown carbon using various solvents does not suffer from the interference by $\mathrm{BC}$ absorption since it can be removed from the solution, and provides detailed spectra information; however, particle size-resolved information is lost [Hecobian et al., 2010].

[4] Of particular interest is the water-soluble component of brown carbon associated with secondary organic aerosols (SOA) in the absence of biomass burning. SOA formation leads to water-soluble organics and is a complex poorly understood process that contributes a substantial fraction to the fine particle mass and affects aerosol scattering, cloud activation and the toxicity properties of fine particles [Hallquist et al., 2009]. In this work, we report online measurements of soluble brown carbon at two urban sites, Pasadena, California and Atlanta, Georgia, to examine the light-absorbing properties and formation process of SOA in cites with contrasting emissions of volatile organic compounds (VOCs).

\section{Methods}

[5] Measurements were carried out in Pasadena, CA (May 15 to June 15, 2010), and Atlanta, GA (Aug 6 to Sep 7, 2010). Pasadena sampling was conducted at the California Institute of Technology, $\sim 16 \mathrm{~km}$ NE of central Los Angeles [Hersey et al., 2011] (here after referred to as the LA site), as part of the CalNex campaign. Due to instrumentation issues, light absorption data from only June 1 to June 15 were analyzed. Atlanta measurements were conducted on the Georgia Institute of Technology campus in central Atlanta and are representative of the Atlanta urban plume [Hennigan et al., 2009]. All data are reported in local time (PDT for LA and EST for Atlanta) and at ambient $\mathrm{T}$ and $\mathrm{p}$. There was no evidence that biomass-burning impacts were significant during either study (auxiliary material). ${ }^{1}$

[6] A Particle-Into-Liquid Sampler (PILS) that continuously transfers ambient $\mathrm{PM}_{2.5}$ to an aqueous flow of purified water was coupled in series with a long-path UV/VIS spectrophotometer and a Total Organic Carbon (TOC) analyzer for measurements of the soluble aerosol light absorption spectra (200-800 nm in solution) and water-soluble organic carbon (WSOC) concentration [Hecobian et al., 2010]. $\mathrm{PM}_{2.5}$ elemental carbon (EC) was quantified semi-continuously with a Sunset Labs OCEC Analyzer (NIOSH 5040 method).

\footnotetext{
${ }^{1}$ Auxiliary materials are available in the HTML. doi:10.1029/ 2011GL049385.
} 

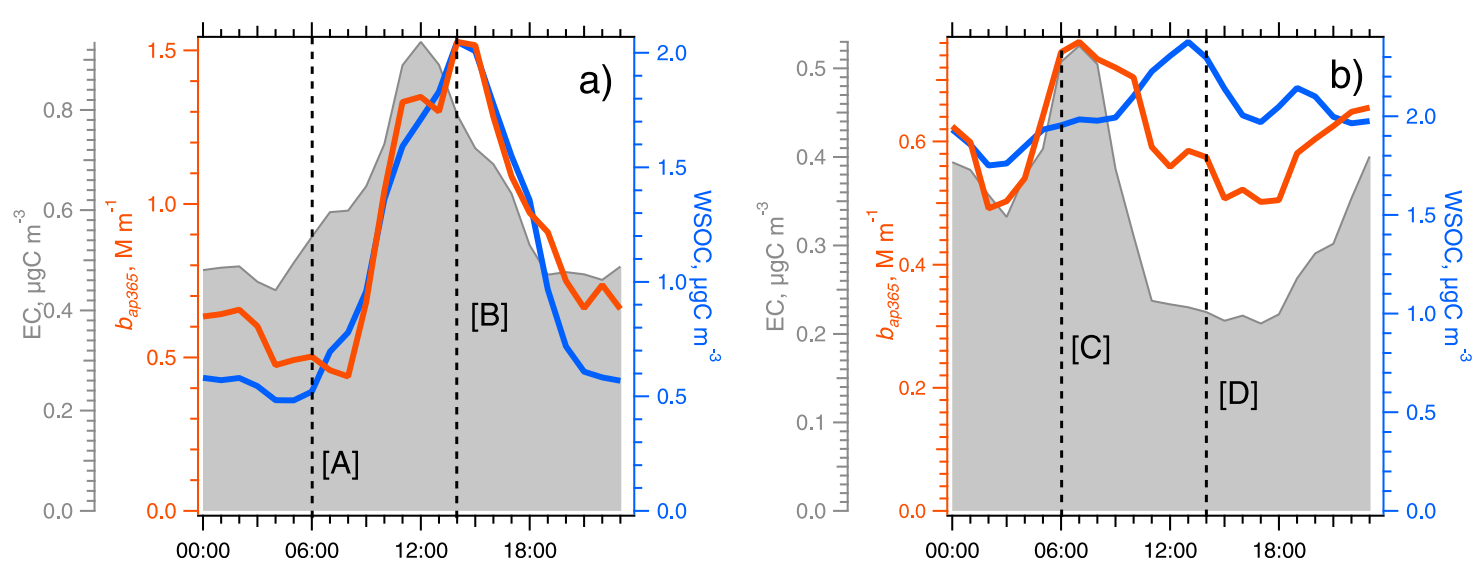

Figure 1. Study mean diurnal profiles of the $\mathrm{PM}_{2.5}$ components; elemental carbon (EC) and the water-soluble extract light absorption at $365 \mathrm{~nm}\left(b_{a p 365}\right)$ and organic carbon mass (WSOC) measured at (a) Pasadena, CA (June 1 to June 15, 2010) and (b) Atlanta, GA (Aug 6 to Sep 7, 2010).

During CalNex, $\mathrm{PM}_{2.5}$ and $\mathrm{PM}_{1}$ were collected with highvolume filter sampling systems for offline chemical analyses. Data from intensive sampling on June 4, 10 and 13, 2010, where filters were changed every $3-6 \mathrm{~h}$, were subsequently analyzed by UPLC/ESI-HR-Q-ToFMS for specific $\mathrm{PM}_{2.5}$ organic compounds [Zhang et al., 2011]. $\mathrm{PM}_{1}$ samples from Jun 4 and 14, 2010 with an integration time of 3-4 h were analyzed for ${ }^{14} \mathrm{C}$ measurements [Szidat et al., 2004]. Similar filter sampling and analysis were not performed in Atlanta. Further measurement details are provided in the auxiliary material.

\section{Results}

\subsection{LA Soluble Brown Carbon}

[7] Example spectra showing the wavelength dependence of absorption for two time periods identified in Figure 1 are shown in Figure 2. Angström exponents $\left(\AA_{a}\right)$ were similar throughout the study at both sites, ranging between roughly 2 and 5 with an LA $\mathscr{A}_{a}$ mean of $3.2 \pm 1.2$. The relatively rapid decrease in absorption with increasing wavelength is the characteristic of brown carbon. For ease of analysis we focus on the absorption averaged between 360 and $370 \mathrm{~nm}\left(b_{a p 365}\right)$ as an overall proxy of soluble brown carbon. $b_{a p 365}$ followed a consistent diurnal trend in LA (Figure 1a) that largely tracked the formation and dispersion of SOA. Enhancement in EC near noon (average increase of $0.48 \mu \mathrm{g} \mathrm{C} \mathrm{m}^{-3}$ ) indicated arrival of the LA plume and was later followed by simultaneous increases in $b_{a p 365}$ and WSOC from a background of $0.5 \mathrm{M} \mathrm{m}^{-1}$ and $0.9 \mu \mathrm{g} \mathrm{C} \mathrm{m}^{-3}$ at $\sim 9: 00$, respectively, to a daily maximum of $1.5 \mathrm{M} \mathrm{m}^{-1}$ and $2.0 \mu \mathrm{g} \mathrm{C} \mathrm{m}^{-3}$, which occurred at 15:00. Brown carbon largely tracked WSOC and other independent measures of SOA throughout the day, indicating a strong association between the two. It is known that incomplete combustion, such as vehicle emissions, also contributes to primary brown carbon [Hecobian et al., 2010]. Pasadena is a receptor of LA emissions. The advection time from LA and photochemical SOA production in early afternoon resulted in overlapping trends in EC and WSOC (SOA), tending to merge primary and secondary sources of brown carbon. SOA formation was the strongest source, indicated by a stronger correlation of brown carbon with WSOC $\left(r^{2}\right.$ of 0.55$)$ than with EC $\left(r^{2}\right.$ of 0.38$)$ and by differences in weekend-weekday data. Reduced weekend traffic (especially diesel) would be expected to reduce primary emission levels, but have less of an influence on secondary formation (WSOC). The amount of $b_{a p 365}$ per EC mass was nearly doubled on the weekend $\left(b_{a p 365} / \mathrm{EC}\right.$ linear regression slope in Table 1), whereas $b_{a p 365}$ to WSOC slopes remained similar, suggesting different sources for brown carbon and EC, but similar secondary production for brown carbon and WSOC.

[8] PAHs are a significant class of SOA precursors in LA [Hersey et al., 2011]. Environmental chamber experiments have shown production of brown SOA involving photooxidation of aromatics under high- $\mathrm{NO}_{\mathrm{x}}$ conditions [Jaoui et al., 2008; Zhong and Jang, 2011]. Table 2 summarizes the correlations between $b_{a p 365}$ and selected nitrogen-

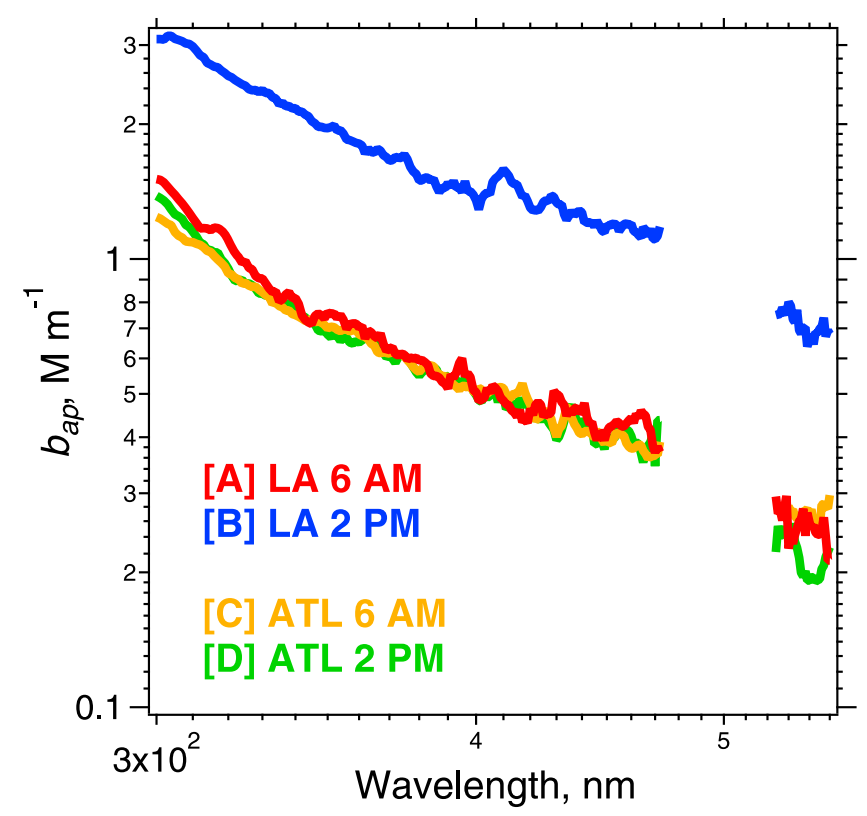

Figure 2. Study mean absorption spectra between wavelengths 300 and $550 \mathrm{~nm}$ at selected time periods (A-D are identified in Figure 1) in Pasadena $(\mathrm{n}=15)$ and Atlanta $(n=29)$. The gaps in the spectra between 475 and $525 \mathrm{~nm}$ are due to instrumentation issues. 
Table 1. Comparison of Mean Properties for All Study Data and for Weekday and Weekend Data ${ }^{\mathrm{a}}$

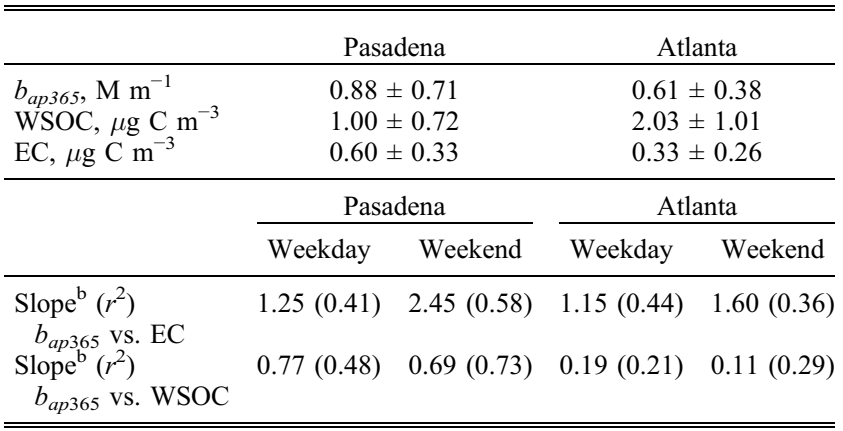

${ }^{\text {a }}$ Pasadena and Atlanta weekend data are from 2 weekends and 5 weekends, respectively.

${ }^{\mathrm{b}}$ Unit: $\mathrm{m}^{2} \mathrm{~g}^{-1} \mathrm{C}$.

containing mono- and poly- aromatic SOA constituents analyzed by UPLC/ESI-HR-Q-ToFMS. Other aromatic SOA components (e.g., benzoic acid) were not correlated with $b_{a p 365 .}$

\subsection{Atlanta Soluble Brown Carbon}

[9] Although a similar spectral dependence of absorption was observed in Atlanta (mean $A_{a}$ at $3.4 \pm 0.7$, Figure 2), association between brown carbon and WSOC in Atlanta was different from LA. Variability of brown carbon in Atlanta was more associated with primary vehicle emissions; brown carbon was better correlated with EC ( $r^{2}$ of 0.50$)$ than with WSOC ( $r^{2}$ of 0.25 ), opposite to LA. The average Atlanta diurnal trends show that brown carbon and WSOC exhibited moderate enhancements at different time periods during the day relative to a high background (Figure $1 \mathrm{~b}$ ). Since the site is located in the urban center, unlike Pasadena as a LA receptor, Atlanta local rush hour is evident by a strong EC enhancement between 5:00 and 8:00. The dominant brown carbon diurnal feature is that it tracks morning rush hour EC. Boundary layer expansion and reduced traffic account for the sharp EC decrease and leveling off in the afternoon to $\sim 0.2 \mu \mathrm{g}$ $\mathrm{C} \mathrm{m}^{-3}$, roughly a third of that recorded in Pasadena. Photochemical SOA production in urban Atlanta is identifiable as the daytime increase in WSOC between 9:00 and 18:00, a $20-30 \%$ enhancement over the regional background observed at a rural site $55 \mathrm{~km}$ northwest of Atlanta (Yorkville, GA). During this period when WSOC (SOA) was photochemically produced within the city, brown carbon only exhibited minor enhancement (Figure 1b). Furthermore, unlike LA where the weekday and weekend $b_{a p 365} /$ WSOC slopes were similar, in Atlanta this slope was much lower on the weekend. In contrast, the $b_{a p 365} / \mathrm{EC}$ slopes were similar in Atlanta on weekday and weekend (Table 1). In both cities, daily enhancements in brown SOA may be from lightabsorbing compounds formed in the gas phase that partition to the particles, such as nitro-aromatics, given that they were produced rapidly. Heterogeneous reactions leading to brown SOA tend to be slower, but may also contribute to brown carbon, especially on a regional basis.

\subsection{Regional Brown Carbon in the Southeast}

[10] Although fresh Atlanta WSOC is less light-absorbing than LA WSOC, our measurements of light-absorbing properties of WSOC throughout the southeastern U.S. show that brown carbon is a ubiquitous component of WSOC
[Hecobian et al., 2010]. Similar analytical measurements of brown carbon $\left(b_{a p 365}\right)$ and WSOC made off-line on aqueous extracts from $\mathrm{PM}_{2.5}$ 24-h integrated filters collected at various sites throughout the southeast showed that $b_{a p 365}$ and WSOC were correlated at all sites (for rural sites $r=0.5$ to 0.7 ; for urban sites $r=0.7$ to 0.9 ). A factor analysis indicated that in summer the variability of $b_{a p 365}$ was linked with aerosol oxalate concentrations [Hecobian et al., 2010]. Although further analysis is needed to understand the source of this brown WSOC and oxalate, the results are consistent with laboratory studies that show water-soluble dicarbonyls, such as glyoxal and methylglyoxal, produced from isoprene oxidation can form brown SOA via aqueous phase reactions, when mixed with a source of nitrogen (e.g. ammonium, amines) [Shapiro et al., 2009; Sareen et al., 2010]. Aqueous reactions are also a known source of oxalate [e.g., Sorooshian et al., 2006]. However, given the relatively slow rate of these brown carbon-forming reactions in the aqueous phase (from several hours to day) [Sareen et al., 2010], and that no concurrent increase in oxalate was observed between 9:00 and 18:00 within Atlanta (not plotted), it appears that this regional formation process differs from the urban brown carbon source that we associate with the fresh daily WSOC production discussed above.

\subsection{Why Is Fresh Atlanta WSOC (SOA) Less Light-Absorbing Than LA?}

[11] Fresh LA WSOC is 4 to 6 times more absorbing per WSOC mass than the fresh Atlanta WSOC. The slope of $b_{a p 365} /$ WSOC in LA ranged from 0.69 (weekdays) to $0.77 \mathrm{~m}^{2}$ $\mathrm{g}^{-1} \mathrm{C}$ (weekends), whereas in Atlanta $b_{a p 365} / \mathrm{WSOC}$ was only between 0.11 (weekends) and $0.19 \mathrm{~m}^{2} \mathrm{~g}^{-1} \mathrm{C}$ (weekdays) (Table 1).

[12] Differences in light-absorbing properties of fresh SOA between LA and Atlanta may be attributed to different SOA precursors within the two urban environments, resulting in different types of SOA, and possibly SOA formation mechanisms. Radiocarbon analysis of CalNex $\mathrm{PM}_{1}$ filters show a significant afternoon enhancement of only fossil carbon; the increase of fossil carbon between 12:00 and 18:00, relative to other times of day, was $\sim 4.5$ times larger than that of modern carbon. Our observed linkage between aromatic photo-oxidation products in a high- $\mathrm{NO}_{\mathrm{x}}$ environment and brown SOA $\left(b_{a p 365}\right)$, and overall correlation of $b_{a p 365}$ with LA WSOC, suggest brown SOA may be a general characteristic of fresh anthropogenic SOA in urban (high $\mathrm{NO}_{\mathrm{x}}$ ) environments. Radiocarbon analysis of Atlanta summertime WSOC has shown that it is largely modern [Weber et al., 2007], consistent with high isoprene emissions in the southeast [Müller et al., 2008]. Thus, one possible reason why urban Atlanta produces less light-absorbing SOA within the city is that biogenic VOCs play a more dominant role.

[13] Chamber experiments have investigated the optical properties of SOA produced from anthropogenic and biogenic VOCs and found greater light absorption from anthropogenic (aromatic) components [Zhong and Jang, 2011; Nakayama

Table 2. Correlations of $b_{a p 365}$ With WSOC and Selected NitroAromatic Compounds

\begin{tabular}{ccccccc}
\hline & WSOC & $\mathrm{C}_{6} \mathrm{H}_{5} \mathrm{NO}_{4}$ & $\mathrm{C}_{7} \mathrm{H}_{5} \mathrm{NO}_{5}$ & $\mathrm{C}_{7} \mathrm{H}_{7} \mathrm{NO}_{3}$ & $\mathrm{C}_{7} \mathrm{H}_{7} \mathrm{NO}_{4}$ & $\mathrm{C}_{10} \mathrm{H}_{7} \mathrm{NO}_{3}$ \\
\hline$r^{2}$ & 0.83 & 0.72 & 0.62 & 0.15 & 0.16 & 0.43 \\
\hline
\end{tabular}


et al., 2010]. Jaoui et al. [2008] found that a significant mass of light-absorbing compounds were formed from irradiation of toluene $/ \alpha$-pinene mixture in the presence of $\mathrm{NO}_{\mathrm{x}}$; however, when isoprene was introduced to the mixture, the SOA became whiter due to faster isoprene oxidation reactions than aromatics, which sequestered $\mathrm{NO}_{\mathrm{x}}$ and consumed the limited oxidants within the chamber. The Jaoui et al. [2008] results are curiously similar to our LA-Atlanta comparison in that fresh SOA formed in an anthropogenic (aromatics)dominated environment is much more light-absorbing than one involving a mix of anthropogenic and biogenic (isoprene) VOCs. However, the Jaoui et al. [2008] experiments were performed under dry $(30 \% \mathrm{RH})$ conditions, and it is known that isoprene and aromatic oxidation in high- $\mathrm{NO}_{\mathrm{x}}$ regimes preferentially leads to low molecular weight (higher vapor pressure) water-soluble carbonyls that can partition to water and form SOA [Ervens et al., 2011]. Thus, if sufficient aerosol water is present, an aqueous SOA route may be important in a high- $\mathrm{NO}_{\mathrm{x}}$ /isoprene environment. Evidence for enhanced partitioning of WSOC to the particle phase has been observed in Atlanta [Hennigan et al., 2009] but not in LA; an analysis of CalNex data suggests the partitioning preference in LA was to the pre-existing organic phase [Ervens et al., 2011]. Other ambient studies have also reported preferential formation of modern (biogenic) SOA in polluted environments [de Gouw et al., 2005; Weber et al., 2007; Hoyle et al., 2011].

[14] In summary, these results suggest that water-soluble brown carbon can be a prevalent component of SOA freshly produced from anthropogenic compounds and a useful tool to investigate SOA formation processes. Applied to a LA-Atlanta comparison, it supports other studies that suggest SOA formed in an anthropogenic/biogenic VOC mixture under high- $\mathrm{NO}_{\mathrm{x}}$ conditions would preferentially generate SOA from the biogenic emissions and alter the SOA properties (e.g., optical) and possibly formation mechanism (e.g., partitioning preference).

[15] Acknowledgments. Georgia Tech investigators were supported by the NSF under grants ATM-0931492 and ATM-0802237. UPLC/ESIHR-Q-ToFMS analyses were conducted in the UNC-Chapel Hill Biomarker Mass Facility located within the Department of Environmental Sciences and Engineering, which is a part of the UNC-Chapel Hill Center for Environmental Health and Susceptibility and is supported by NIEHS (grant 5P20ES10126)

[16] The Editor thanks two anonymous reviewers for their assistance in evaluating this paper.

\section{References}

Andreae, M., and A. Gelencser (2006), Black carbon or brown carbon? The nature of light-absorbing carbonaceous aerosols, Atmos. Chem. Phys., 6, 3131-3148, doi:10.5194/acp-6-3131-2006.

Bones, D. L., D. K. Henricksen, S. A. Mang, M. Gonsior, A. P. Bateman, T. B. Nguyen, W. J. Cooper, and S. A. Nizkorodov (2010), Effect of slow aging reactions on optical properties of secondary organic aerosol prepared by oxidation of selected monoterpenes, J. Geophys. Res., 115, D05203, doi:10.1029/2009JD012864.

de Gouw, J. A., et al. (2005), The budget of organic carbon in a polluted atmosphere: Results from the New England Air Quality Study in 2002, J. Geophys. Res., 110, D16305, doi:10.1029/2004JD005623.

Ervens, B., B. Turpin, and R. J. Weber (2011), Secondary organic aerosol formation in cloud drops and aqueous particles (aqSOA): A review of laboratory, field and model studies, Atmos. Chem. Phys. Discuss., 11, 22,301-22,383, doi:10.5194/acpd-11-22301-2011.

Gupta, P., W. P. Harger, and J. Arey (1996), The contribution of nitro- and methylnitro-naphthalenes to the vapor-phase mutagenicity of ambient air samples, Atmos. Environ., 30, 3157-3166, doi:10.1016/1352-2310(96) 00024-6.
Hallquist, M., et al. (2009), The formation, properties and impact of secondary organic aerosol: current and emerging issues, Atmos. Chem. Phys., 9, 5155-5236, doi:10.5194/acp-9-5155-2009.

Hecobian, A., X. Zhang, M. Zheng, N. Frank, E. S. Edgerton, and R. J. Weber (2010), Water-soluble organic aerosol material and the lightabsorption characteristics of aqueous extracts measured over the southeastern United States, Atmos. Chem. Phys., 10, 5965-5977, doi:10.5194/acp-10-5965-2010

Hennigan, C. J., M. H. Bergin, A. G. Russell, A. Nenes, and R. J. Weber (2009), Gas/particle partitioning of water-soluble organic aerosol in Atlanta, Atmos. Chem. Phys., 9, 3613-3628, doi:10.5194/acp-9-36132009.

Hersey, S. P., J. S. Craven, K. A. Schilling, A. R. Metcalf, A. Sorooshian, M. N. Chan, R. C. Flagan, and J. H. Seinfeld (2011), The Pasadena Aerosol Characterization Observatory (PACO): Chemical and physical analysis of the western Los Angeles Basin aerosol, Atmos. Chem. Phys., 11, 7417-7443, doi:10.5194/acp-11-7417-2011.

Hoyle, C. R., et al. (2011), A review of the anthropogenic influence of biogenic secondary organic aerosol, Atmos. Chem. Phys., 11, 321-343, doi:10.5194/acp-11-321-2011.

Jacobson, M. Z. (1999), Isolating nitrated and aromatic aerosols and nitrated aromatic gases as sources of ultraviolet light absorption, J. Geophys. Res., 104, 3527-3542, doi:10.1029/1998JD100054.

Jaoui, M., E. O. Edney, T. E. Kleindienst, M. Lewandowski, J. H Offenberg, J. D. Surratt, and J. H. Seinfeld (2008), Formation of secondary organic aerosol from irradiated a-pinene/toluene/NOx mixtures and the effect of isoprene and sulfur dioxide, J. Geophys. Res., 113, D09303, doi:10.1029/2007JD009426.

Müller, J. F., et al. (2008), Global isoprene emissions estimated using MEGAN, ECMWF analyses and a detailed canopy environment model, Atmos. Chem. Phys., 8, 1329-1341, doi:10.5194/acp-8-1329-2008.

Nakayama, T., Y. Matsumi, K. Sato, T. Imamura, A. Yamazaki, and A. Uchiyama (2010), Laboratory studies on optical properties of secondary organic aerosols generated during the photooxidation of toluene and the ozonolysis of a-pinene, J. Geophys. Res., 115, D24204, doi:10.1029/ 2010JD014387.

Park, R. J., M. J. Kim, J. I. Jeong, D. Yooun, and S. Kim (2010), A contribution of brown carbon aerosol to the aerosol light absorption and its radiative forcing in East Asia, Atmos. Environ., 44, 1414-1421, doi:10.1016/j.atmosenv.2010.01.042.

Sandradewi, J., A. S. H. Prevot, E. Weingartner, R. Schmidhauser, M. Gysel, and U. Baltensperger (2008), A study of wood burning and traffic aerosols in an alpine valley using a multi-wavelength aethalometer, Atmos. Environ., 42, 101-112, doi:10.1016/j.atmosenv.2007.09.034.

Sareen, N., et al. (2010), Secondary organic material formed by methylglyoxal in aqueous aerosol mimics, Atmos. Chem. Phys., 10, 997-1016, doi:10.5194/acp-10-997-2010.

Shapiro, E. L., J. Szprengiel, N. Sareen, C. N. Jen, M. R. Giordano, and V. F. McNeill (2009), Light-absorbing secondary organic material formed by glyoxal in aqueous aerosol mimics, Atmos. Chem. Phys., 9, 2289-2300, doi:10.5194/acp-9-2289-2009.

Sorooshian, A., et al. (2006), Oxalic acid in clear and cloudy atmospheres: Analysis of data from International Consortium for Atmospheric Research on Transport and Transformation 2004, J. Geophys. Res., 111, D23S45, doi:10.1029/2005JD006880.

Szidat, S., et al. (2004), Source apportionment of aerosols by ${ }^{14} \mathrm{C}$ measurements in different carbonaceous particle fractions, Radiocarbon, 46, $475-484$.

Weber, R. J., et al. (2007), A study of secondary organic aerosol formation in the anthropogenic-influenced southeastern United States, J. Geophys. Res., 112, D13302, doi:10.1029/2007JD008408.

Zhang, H., J. D. Surratt, Y. H. Lin, J. Bapat, and R. M. Kamens (2011), Effect of relative humidity on SOA formation from isoprene/NO photooxidation: enhancement of 2-methylglyceric acid and its corresponding oligoesters under dry conditions, Atmos. Chem. Phys., 11, 6411-6424, doi:10.5194/acp-11-6411-2011.

Zhong, M., and M. Jang (2011), Light absorption coefficient measurement of SOA using a UV-Visible spectrometer connected with an integrating sphere, Atmos. Environ., 45, 4263-4271, doi:10.1016/j.atmosenv.2011. 04.082 .

Y.-H. Lin and J. D. Surratt, Department of Environmental Sciences and Engineering, Gillings School of Global Public Heath, University of North Carolina, Chapel Hill, NC 27599, USA.

A. S. H. Prévôt and P. Zotter, Laboratory of Atmospheric Chemistry, Paul Scherrer Institut, Villigen CH-5232, Switzerland.

R. J. Weber and X. Zhang, School of Earth and Atmospheric Sciences, Georgia Institute of Technology, Atlanta, GA 30332, USA. (xzhang3@ mail.gatech.edu) 